\title{
Avaliação da aderência microbiana e rugosidade superficial de resina acrílica quimicamente ativada após ciclagem com diferentes soluções desinfetantes
}

\section{Evaluation of microbial adherence and superficial roughness of chemically activated acrylic resin after cycling with different disinfectant solutions}

\section{Jane Rezende de OLIVEIRA}

Aluna - Curso de Especialização em Odontopediatria - Faculdade de Ciências da Saúde - Universidade do Vale do Paraíba - UNIVAP - São José dos Campos - SP - Brasil

\section{Thaís Cachuté PARADELLA}

Doutoranda - Programa de Pós-Graduação em Biopatologia Bucal - Área de Concentração Biopatologia Bucal Faculdade de Odontologia de São José dos Campos - Universidade Estadual Paulista - UNESP - São José dos Campos $-\mathrm{SP}-$ Brasil

\section{Marcos Augusto do REGO}

Professor Doutor - Curso de Especialização em Odontopediatria - Faculdade de Ciências da Saúde - Universidade do Vale do Paraíba - UNIVAP - São José dos Campos - SP - Brasil

\section{Cristiane Yumi KOGA-ITO}

Professora Doutora - Disciplina de Microbiologia e Imunologia - Departamento de Biociências e Diagnóstico Bucal Faculdade de Odontologia de São José dos Campos - Universidade Estadual Paulista - UNESP - São José dos Campos $-\mathrm{SP}$ - Brasil

\section{Antonio Olavo Cardoso JORGE}

Professor Titular - Disciplina de Microbiologia e Imunologia - Departamento de Biociências e Diagnóstico Bucal Faculdade de Odontologia de São José dos Campos - Universidade Estadual Paulista UNESP - São José dos Campos $-\mathrm{SP}$ - Brasil

\section{Resumo}

O objetivo do estudo foi analisar a rugosidade superficial e a aderência de Staphylococcus aureus (ATCC 6538) e Candida albicans (F-72) em placas de resina acrílica quimicamente ativada antes e após ciclagem com diferentes soluções desinfetantes. Para isso, quarenta corpos-de-prova de resina acrílica de $4 \mathrm{~mm}^{2}$ foram confeccionados utilizando uma matriz metálica. Os corpos-de-prova receberam polimento químico, tiveram a rugosidade superficial mensurada, foram esterilizados e a seguir imersos em caldo infusão cérebro-coração (BHI) para S. aureus e caldo Sabouraud para C. albicans, juntamente com suspensão padronizada $\left(10^{6}\right.$ células $\left./ \mathrm{mL}\right)$ de cada microrganismo. Após $24 \mathrm{~h} / 37^{\circ} \mathrm{C}$, os microrganismos aderidos aos corpos-de-prova foram dispersos, diluídos e semeados em meio de cultura para determinar o número de unidades formadoras de colônias (UFC/mL). Em seguida, cada corpo-de-prova foi ciclado nas seguintes soluções por 28 dias: água destilada (grupo controle), gluconato de clorexidina a $0,12 \%$ (grupo clorexidina), vinagre (grupo vinagre) e cloreto de cetilpiridínio (grupo cloreto). Após ciclagem, o teste de aderência e o teste de rugosidade foram repetidos. Os resultados foram analisados estatisticamente pelo teste t de Student ao nível de significância de 5\% e somente o grupo clorexidina apresentou diferença estatística significante, com a diminuição nos valores de aderência em relação aos demais grupos após a ciclagem. Em relação à rugosidade, nenhum grupo apresentou alteração significativa após a ciclagem. Concluiu-se que o gluconato de clorexidina a $0,12 \%$ alterou a aderência de $S$. aureus e C. albicans à resina acrílica, porém sem afetar sua rugosidade superficial.

\section{UNITERMOS}

Resina acrílica; Staphylococcus aureus; Candida albicans; aderência bacteriana. 


\section{INTRODUÇÃo}

A Odontologia contemporânea se depara com o aumento de pacientes cada vez mais jovens, a procura de correções ortodônticas. No caso de dentição decídua, o aparelho mais indicado é o removível, porém devido à sua facilidade de colocação e remoção, muitas vezes este aparelho pode ser armazenado sem os devidos cuidados, podendo causar danos à saúde bucal do indivíduo. Com o aumento global na incidência de doenças infecto-contagiosas das mais variadas etiologias, sugere-se a necessidade de adotar mecanismos de controle de microrganismos tanto para o profissional e sua equipe, quanto para o paciente (Gonçalves et al. ${ }^{5}$, 1996; Buffara \& Portela $\left.{ }^{2}, 2000\right)$.

Os aparelhos ortodônticos removíveis são constituídos de resina acrílica, sendo importante o estudo da influência de microrganismos patogênicos presentes na cavidade bucal na resina acrílica, uma vez que estes aparelhos podem tornar-se nichos bacterianos, levando a sérios danos aos tecidos bucais, pois nem sempre o paciente ortodôntico é corretamente instruído para a desinfecção de seus aparelhos ortodônticos (Rego et al. ${ }^{13}$, 2005). Diferenças na topografia da superfície dos aparelhos podem influenciar a capacidade de aderência dos microrganismos na superfície (* vide obs no final) (KULAK et al. ${ }^{7}, 1997$; RADFORD et al. ${ }^{11}, 1998$; LAMFON et al. $\left.{ }^{8}, 2003\right)$. A rugosidade superficial é uma característica importante de materiais dentários, uma vez que o valor de $0,2 \mu \mathrm{m}$ de rugosidade superficial ( $\mathrm{Ra}$ ) é considerado o limite abaixo do qual não é esperado aderência bacteriana (ZISSIS et al. ${ }^{21}, 2000$ ), havendo portanto direta correlação entre Ra e aderência bacteriana, uma vez que está claro que existe uma forte relação de Ra com aderência bacteriana inicial, assim como sua estagnação (REGO et al. ${ }^{12}, 2005$ ).

A esterilização/desinfecção por métodos físicos de aparelhos ortodônticos removíveis é inviável, pois o ponto de ebulição do monômero que compõe a resina acrílica é de $103,3{ }^{\circ} \mathrm{C}$ e a temperatura de distorção térmica é relativamente baixa $\left(95^{\circ} \mathrm{C}\right)$. Desta forma, a utilização de desinfecção química se faz necessária (ASAD et al. ${ }^{1}, 1993$; Rodrigues et al. $\left.{ }^{13}, 1994\right)$.

Para a desinfecção de aparelhos ortodônticos removíveis, diversos agentes químicos desinfetantes podem ser utilizados. Deve-se, entretanto, conhecer as propriedades importantes dos produtos como seus mecanismos de ação sobre os microrganismos, sua toxicidade para o manipulador e sua ação deletérica para o material a ser desinfetado. A escolha adequada do desinfetante proporciona o sucesso da desinfecção (Buffara \& Portella², 2000; Silva \& Jorge $\left.^{14}, 2002\right)$.

Dentre as várias espécies microbianas presentes na cavidade bucal, Candida albicans é a espécie fúngica mais comumente isolada de casos de candidose. $C$. albicans adere-se à resina acrílica, o que pode propiciar o desenvolvimento desta patologia (Williams \& Lewis $^{20}, 2000$ ), além de ser uma espécie microbiana comumente utilizada em estudos sobre desinfecção em Odontologia, pois certos agentes desinfetantes são ineficazes frente a infecções micóticas (Chibebe Junior $\&$ Pallos $^{4}$, 2001; Silva \& Jorge ${ }^{14}$, 2002).

Staphylococcus aureus é uma espécie bacteriana relacionada a diversas patologias devido ao grande número de fatores de virulência. Indivíduos saudáveis podem ser portadores de cepas de $S$. aureus na mucosa nasal e bucal, sendo este microrganismo altamente correlacionado com infecções hospitalares. Muitos casos são citados na literatura de crianças com patologias severas (incluindo pneumonias e intoxicações alimentares, dentre outras), cujo agente etiológico era S. aureus, sendo fácil sua transmissão entre indivíduos (Westphal et al. ${ }^{18}, 2000$ ).

O objetivo deste trabalho foi avaliar a aderência de C. albicans e $S$. aureus à resina acrílica quimicamente ativada, bem como a rugosidade superficial após a ciclagem com diferentes soluções antimicrobianas, no intuito de avaliar a ação dos métodos sobre as propriedades físicas do material e sobre a aderência de microrganismos.

\section{Material e método}

Quarenta corpos-de-prova de resina acrílica quimicamente ativada foram confeccionados com resina incolor quimicamente polimerizável (Clássico, Produtos Odontológicos) com $4 \mathrm{~mm}$ de diâmetro, utilizandose matriz metálica. A seguir, foi realizado polimento químico por meio do dispositivo PQ Termotron 9000 (Termotron do Brasil, Piracicaba), que consiste no aquecimento automático do fluido para polimento químico à base de metil-metacrilato (Poliquim Artigos Odontológicos Clássico). A seguir, os corpos-de-prova foram imersos durante 10 segundos, secos e lavados em água corrente durante 20 segundos (Rego et al. ${ }^{12}$, 2005; Goiato et al. ${ }^{6}, 2006$ ). 
Os corpos-de-prova tiveram a rugosidade superficial inicial medida no Laboratório de medição de superfícies ópticas do Instituto de Estudos Avançados do Centro Técnico Aeroespacial (IEAv-CTA), utilizando-se Rugosímetro Mahr-Perthen, modelo S8P (Germany), com ponteira óptica Focodyn, com comprimento total (LT) igual a $1,750 \mathrm{~mm}$ e desgaste de flanco (VB) igual a $250 \mu \mathrm{m}$. Foram feitas três mensurações de rugosidade por corpo-de-prova, obtendo-se a média de rugosidade ( $\mathrm{Ra}$ ) para cada corpo-de-prova. Após a medida da rugosidade inicial, os corpos-de-prova foram colocados em recipientes de vidro contendo solução fisiológica e esterilizados em autoclave $\left(121^{\circ} \mathrm{C} / 20 \mathrm{~min}\right)$ e submetidos ao teste de aderência inicial.

Para o teste de aderência inicial, foram utilizadas amostras-padrão de Staphylococcus aureus (ATCC 6538) e Candida albicans (F-72), provenientes do Laboratório de Microbiologia da Faculdade de Odontologia de São José dos Campos - UNESP.

A amostra de $S$. aureus foi mantida em ágar infusão cérebro coração (BHI - Acumedia Manufacturers, Michigan, USA) inclinado, sendo semeada em placas de ágar infusão cérebro e coração (BHI) e incubadas a $37^{\circ} \mathrm{C}$ por $24 \mathrm{hs}$. A amostra de C. albicans foi mantida em ágar-Sabouraud dextrose (Difco - Becton Dickinson and Company, USA) inclinado e repicada em placas com ágar Sabouraud dextrose, sendo incubada a $37^{\circ} \mathrm{C}$ por 24 horas.

Para realização dos testes, foram preparadas suspensões de $S$. aureus e de C. albicans contendo $10^{6}$ células $/ \mathrm{mL}$ cada uma. As suspensões foram padronizadas por análise em espectrofotômetro (Shimadzu modelo UV-1203, Kyoto, Japão), considerando-se comprimento de onda de $490 \mathrm{~nm}$ para $S$. aureus e 530 $\mathrm{nm}$ para $C$. albicans.

O teste de aderência foi realizado em ambiente estéril (câmara de fluxo laminar), utilizando-se placas de cultura de células de 24 poços (Costar, Cambridge, Massachusetts, USA). Para avaliação da aderência de $S$. aureus foram colocados em cada poço: um corpode-prova, $1,5 \mathrm{~mL}$ de caldo infusão cérebro e coração (BHI), 0,1 mL da suspensão padronizada de $S$. aureus. Para avaliação da aderência de C. albicans foram colocados em cada poço: um corpo-de-prova, $1,5 \mathrm{~mL}$ de caldo Sabouraud e 0,1 mL da suspensão padronizada de $C$. albicans. As placas foram tampadas e incubadas a $37^{\circ} \mathrm{C}$ por 24 horas.

A seguir, os corpos-de-prova foram removidos, lavados com $1 \mathrm{~mL}$ de água destilada estéril e colocados em tubos de ensaio contendo $1 \mathrm{~mL}$ de solução fisiológica $(\mathrm{NaCl} 0,85 \%)$ e pérolas de vidro, sendo o conjunto agitado em um agitador de tubos (Vortex) por 60 segundos. Microrganismos que aderiram aos corpos-de-prova foram dispersos, diluídos $10 \mathrm{e}$ 100 vezes e transferidos, em duplicata, para placas com ágar infusão cérebro e coração (BHI) para $S$. aureus ou placas de ágar Sabouraud dextrose para C. albicans. Após 24 horas, o número de unidades formadoras de colônias (UFC/mL) foi determinado para cada espécime. As placas escolhidas para contagem foram aquelas que apresentavam entre 30 e 300 colônias.

Em seguida, os corpos-de-prova foram divididos em grupos $(n=10)$, conforme a solução utilizada para ciclagem: Grupo Controle (água destilada), Grupo Vinagre (Vinagre Agrin Claro Fermentado acético de álcool 100\% - Galo de Barcelos, Brasil), Grupo Clorexidina (Gluconato de clorexidina a $0,12 \%$ - Colgate Palmolive Ltda., Brasil) e Grupo Cloreto (Cloreto de cetilpiridínio a 0,05\%, Sanofi-Aventis Ltda., Brasil). A ciclagem consistiu de imersão do corpo-de-prova em 10 mL da solução por 10 minutos três vezes ao dia e em seguida sendo mantido em recipiente fechado. Este ciclo foi realizado durante 28 dias, tomando-se o cuidado de trocar as soluções a cada procedimento executado.

Após a ciclagem, os corpos-de-prova foram novamente submetidos à mensuração da rugosidade superficial e ao teste de aderência, conforme descrito anteriormente. O número de $\mathrm{UFC} / \mathrm{mL}$ inicial e final foi transformado em logarítimo de base 10 e analisados estatisticamente pelo teste t de Student ao nível de 5\% de significância, assim como as médias de rugosidade (Ra) inicial e de cada grupo.

\section{Resultados}

Os resultados da rugosidade superficial $(\mathrm{Ra})$ antes e após a ciclagem dos grupos experimentais estão descritos na Tabela 1, bem como o resultado o teste t de Student. 
Tabela 1 - Média e desvio padrão da rugosidade superficial (Ra) inicial e final dos corpos-de-prova antes e após ciclagem com diferentes desinfetantes ( $\mu \mathrm{m})$

\begin{tabular}{|c|c|c|c|}
\hline Solução desinfetante & $\begin{array}{l}\text { Ra inicial média } \\
\text { (土desvio padrão) }\end{array}$ & $\begin{array}{l}\text { Ra final média } \\
\text { ( } \pm \text { desvio padrão) }\end{array}$ & Valor de $t^{*}$ \\
\hline Grupo Controle & $3,01( \pm 2,26)$ & $3,22( \pm 2,02)$ & $-1,35$ \\
\hline Grupo Vinagre & $3,26( \pm 2,21)$ & $3,33( \pm 2,09)$ & $-0,23$ \\
\hline Grupo Clorexidina & $2,63( \pm 2,00)$ & $2,71( \pm 1,70)$ & $-0,27$ \\
\hline Grupo Cloreto & $3,33( \pm 2,09)$ & $3,44( \pm 3,40)$ & $-0,80$ \\
\hline
\end{tabular}

* t crítico $\geq 2,26$

A análise dos dados por meio do teste t de Student comparou os valores de rugosidade e UFC $/ \mathrm{mL}$ antes e após a ciclagem com as diferentes soluções. Os valores de $\mathrm{t}$ calculados por grupo foram comparados com o valor de $t$ crítico $(2,26)$. Valores iguais ou superiores ao $t$ crítico indicariam diferenças estatísticas significantes. Em relação à rugosidade, não houve diferenças estatísticas significantes entre os grupos. Também foi realizada a análise individual em cada grupo, comparando-se os valores de rugosidade antes e depois da ciclagem. Não houve diferença estatística significante nos valores de $\mathrm{Ra}$ antes e após a cicalgem.

Os resultados de aderência de $S$. aureus por grupo estão descritos na Tabela 2.
Em relação à aderência de $S$. aureus, somente o grupo Clorexidina apresentou diferença estatística significante, com menor número de UFC/mL após a ciclagem com o produto, pois o valor de t para o grupo Clorexidina $(11,49)$ foi maior que o valor de t crítico $(2,26)$. Todos os demais grupos não apresentaram diferenças estatísticas significantes, comparando-se os valores de $\mathrm{t}$ obtidos por grupo com o valor de $\mathrm{t}$ crítico. Na análise individual por grupo, não houve diferença nos valores de aderência antes e após a ciclagem, em todos os grupos, exceto no grupo Clorexidina. Os resultados de aderência de $C$. albicans por grupo estão descritos na Tabela 3.

Tabela 2 - Média e desvio padrão dos valores de aderência inicial e final de S. aureus nos corpos-de-prova antes e após ciclagem com diferentes desinfetantes (UFC/mL transformados em logaritmo de base 10)

\begin{tabular}{c|c|c|c}
\hline Solução desinfetante & $\begin{array}{c}\text { Aderência inicial média } \\
\text { ( } \pm \text { desvio padrão) }\end{array}$ & $\begin{array}{c}\text { Aderência final média } \\
\text { ( } \pm \text { desvio padrão) }\end{array}$ & Valor de t \\
\hline Grupo Controle & $6,51( \pm 0,31)$ & $6,53( \pm 0,27)$ & $-0,65$ \\
Grupo Vinagre & $6,69( \pm 0,33)$ & $6,41( \pm 0,51)$ & 1,88 \\
Grupo Clorexidina & $6,58( \pm 0,23)$ & $5,01( \pm 0,42)$ & 11,49 \\
\hline Grupo Cloreto & $6,56( \pm 0,26)$ & $6,22( \pm 0,48)$ & 1,89 \\
\hline
\end{tabular}

* $\mathrm{t}$ crítico $\geq 2,26$

Tabela 3 - Média e desvio padrão dos valores de aderência inicial e final de C. albicans nos corpos-de-prova antes e após ciclagem com diferentes desinfetantes (UFC/mL transformados em logaritmo de base 10)

\begin{tabular}{c|c|c|c}
\hline Solução desinfetante & $\begin{array}{c}\text { Aderência inicial média } \\
\text { ( } \pm \text { desvio padrão) }\end{array}$ & $\begin{array}{c}\text { Aderência final média } \\
\text { ( } \pm \text { desvio padrão) }\end{array}$ & Valor de t \\
\hline Grupo Controle & $4,68( \pm 0,27)$ & $4,65( \pm 0,30)$ & 1,57 \\
Grupo Vinagre & $4,13( \pm 0,52)$ & $4,24( \pm 0,54)$ & $-1,12$ \\
Grupo Clorexidina & $4,86( \pm 0,70)$ & $4,16( \pm 0,59)$ & 5,33 \\
\hline Grupo Cloreto & $4,43( \pm 0,40)$ & $4,31( \pm 0,57)$ & 1,08 \\
\hline
\end{tabular}

* t crítico $\geq 2,26$ 
Em relação à aderência de $C$. albicans, somente o grupo Clorexidina apresentou diferença estatística significante, pois o valor de $\mathrm{t}$ no grupo Clorexidina $(5,33)$ foi maior do que o valor de $t$ crítico $(2,26)$ e na análise individual por grupo, não houve diferença nos valores de aderência antes e depois da ciclagem, em todos os grupos, com exceção do grupo Clorexidina.

\section{Discussão}

A prática odontológica envolve alto risco de contaminação microbiana devido ao frequiente contato com sangue e saliva. Desta forma, a aplicação de medidas universais de biossegurança, como a utilização de medidas criteriosas de desinfecção, é de importância fundamental para prevenir a contaminação cruzada entre pacientes e profissionais do consultório e laboratórios. Todas as moldagens, modelos de gesso, próteses e aparelhos devem ser adequadamente desinfetados antes de serem entregues ao paciente ou a protéticos. Materiais de moldagem são invariavelmente contaminados por saliva, biofilme dentário e ocasionalmente sangue e modelos de gesso obtidos destes materiais podem também ser contaminados. Uma vez que aparelhos ortodônticos são confeccionados sobre modelos de gesso, espera-se que os mesmos estejam contaminados. Itens de resina acrílica são considerados artigos semi-críticos uma vez que entram em contato com mucosa e assim, devem ser submetidos a esterilização ou desinfecção de alto grau. No entanto, a resina acrílica é um material termosensível e não pode ser submetida a nenhum processo de desinfecção envolvendo altas temperaturas, sendo portanto necessário o uso de soluções desinfetantes. Além disso, a resina acrílica tem capacidade de absorção de líquidos e devido a esta propriedade, aparelhos ortodônticos removíveis colocados na boca do paciente absorvem saliva, o qual é um fluido contaminado. Assim, desinfetantes químicos utilizados em aparelhos ortodônticos removíveis devem ser seguramente atóxicos devido ao risco de resíduos do produto serem liberados na cavidade bucal (Chassot et al. ${ }^{3}, 2006$ ).

Aparelhos ortodônticos removíveis confeccionados em resina acrílica podem transformar-se em nichos microbianos, se uma correta desinfecção destes aparelhos não for realizada. No entanto, a utilização contínua de soluções desinfetantes pode alterar a topografia destes aparelhos, modificando sua rugosidade superficial. Desta forma, pretendeu-se neste estudo estudar o efeito da utilização prolongada de soluções desinfetantes na aderência e rugosidade de $S$. aureus e C. albicans em resina acrílica quimicamente ativada. A utilização prolongada foi simulada por meio da ciclagem com diferentes soluções desinfetantes, sendo o grupo controle composto por ciclagem em água destilada.

A Sociedade Alemã para Higiene e Microbiologia (German Society for Higiene and Microbiology) recomenda que em testes microbiológicos para estudos de desinfecção sejam utilizados $S$. aureus e $C$. albicans. $S$. aureus é microrganismo com alto número de fatores de virulência e resistente a muitas soluções desinfetantes. C. albicans mostra-se capaz de aderir fortemente ao polimetilmetacrilato, que compões a resin acrílica. A adesão ao acrílico é provavelmente mediada por uma adesina protéica multifuncional, que tem sido identificada na superfície de hifas de C. albicans. Esta adesão específica ao acrílico confere uma vantagem ecológica à $C$. albicans nos usuários de aparelhos ortodônticos removíveis pois a espécie pode permanecer na boca independente da mucosa bucal (McCullough et al. ${ }^{9}$, 1996; Wichelhaus et al. ${ }^{19}$, 2006).

Os resultados deste estudo demonstram que somente a ciclagem com gluconato de clorexidina (grupo Clorexidina) diminuiu a aderência de $S$. aureus e $C$. albicans à superfície de resina acrílica quimicamente ativada, porém sem alterar sua rugosidade. Isto pode se dar ao fato desta solução apresentar uma propriedade chamada substantividade, que permite sua lenta liberação em períodos de até 12 horas (Vianna et al. ${ }^{17}$, 2004). Todas as demais soluções desinfetantes não diminuíram a aderência dos microrganismos testados à resina acrílica.

Em relação à rugosidade, não houve diferença entre os grupos, bem como entre os valores de Ra inicial e Ra após ciclagem. Estes resultados corroboram os obtidos por Moura et al. ${ }^{10}$ (2006), no qual afirmam que a rugosidade não interfere na aderência de $C$. albicans à superfície da resina acrílica. Os autores afirmaram que somente a saliva interfere na aderência de $C$. albicans à superfície de resina acrílica, mas a rugosidade superficial e a energia de superfície não têm influência na aderência deste microrganismo ao material. Em um outro estudo, Spiechowicz et al. ${ }^{15}$ (1990), afirmaram que a clorexidina foi totalmente eficaz em inibir a aderência de $C$. albicans à superfície de resina acrílica por um período de até 8 dias.

No entanto, no estudo de Tawara et al. ${ }^{16}$ (1996), o uso de soluções desinfetantes durante 15 dias não alterou a aderência de $S$. aureus e $C$. albicans à superfície de resina acrílica. Os autores afirmaram que a saliva tem um papel importante no aumento da aderência 
AVALIAÇÃO DA ADERÊNCIA MICROBIANA E RUGOSIDADE SUPERFICIAL DE RESINA ACRÍLICA QUIMICAMENTE ATIVADA APÓS CICLAGEM COM DIFERENTES SOLUÇÕES DESINFETANTES

destes microrganismos à resina acrílica, resultados estes corroborados por Moura et al..$^{10}$ (2006). No presente estudo, a saliva não foi utilizada como controle, mas sim a água destilada. Desta forma, mais estudos devem ser realizados sobre a influência da saliva na aderência destes microrganismos à resina acrílica.

\section{Conclusão}

Com as limitações deste estudo, foi possível concluir que não houve diferença na rugosidade superficial de resina acrílica antes e depois da ciclagem com diferentes soluções desinfetantes e somente a ciclagem com gluconato de clorexidina a $0,12 \%$ alterou a aderência de $S$. aureus e $C$. albicans à superfície de resina acrílica.

\section{Agradecimentos}

Os autores gostaria de agradecer ao Sr. Fábio Dondeo do Instituto de Estudos Avançados do Centro Técnico Aeroespacial (IEAv-CTA), São José dos Campos, São Paulo, Brasil, pelo auxílio com as medições de rugosidade superficial e a Fernando Augusto Cervantes Garcia de Sousa pela auxílio com a análise estatística.

\begin{abstract}
The purpose of this study was to analyze the superficial roughness and adherence of Staphylococcus aureus (ATCC 6538) and Candida albicans (F-72) to chemically activated acrylic resin before and after cycling with different anti-septic solutions. Forty samples of acrylic resin of $4 \mathrm{~mm}^{2}$ were confectioned using a stainless steel matrix. The samples received chemical polishing, had their superficial roughness measured, were sterilized and then immersed in brain heart infusion broth (BHI) for S. aureus and Sabouraud broth for C. albicans, together with a standard suspension $\left(10^{6} \mathrm{cells} / \mathrm{mL}\right)$ of each microorganism. After $24 \mathrm{~h} / 37^{\circ} \mathrm{C}$, microorganisms adhered to the samples were dispersed, diluted and evaluated by plating method to determine the number of colony formatting unit (cfu/mL). After that, each specimen was cycled in the following anti-septic solution for 28 days $(n=10)$ : distilled water (control group), $0.12 \%$ gluconate chlorexidine (chlorexidine group), vinegar (vinegar group) and cetil-piridinic chloride (chloride group). After cycling, superficial roughness testing and adherence testing were repeated. Results were statiscally analyzed according to Student t test at $5 \%$ level of confidence and only chlorexidine group presented statistically significant difference $(p<0.05)$, with lower adherence values in relation to the other groups after cycling. Regarding roughness, none of the groups presented significant alteration after cycling. It was concluded that $0.12 \%$ gluconate chlorexidine altered adherence of $S$. aureus $e$ C. albicans to acrylic resin, but not affecting its superficial roughness.
\end{abstract}

\title{
UNITERMS
}

Acrylic resin; Staphylococcus aureus; Candida albicans; bacterial adhesion

\section{REFERÊNCIAS}

1. Asad T, Watkinson AC, Huggett R. The effects of various solutions on the surface hardness of an acrylic resin denture base material. Int J Prosthodont 1993 Dec; 6(1):9-12.

2. Buffara WM, Portella MQ. Controle de infecção em ortodontia. Ortodontia 2000, maio/ago; 33(2):77-85.

3. Chassot ALC, Poisl MIP, Samuel SMW. In Vivo and In Vitro evaluation of the efficacy of a peracetic acid-based disinfectant for decontamination of acrylic resins. Braz Dent J 2006; 17(2):117-21.

4. Chibebe Junior J, Pallos D. Avaliação da esterilização de escovas dentais em forno de microondas (estudo in vitro). Rev Biociênc 2001 jul./dez; 7(2):39-42.

5. Gonçalves ACS, Travassos DV, Silva M. Biossegurança do exercício da odontologia. RPG ver pós-grad 1996 jul./set.; 3(3):242-5.
6. Goiato MC, Vedovatto E, Amantéia DCZ, Gennari Filho H, Marinho MLVD. Análise da movimentação dos dentes artificiais em próteses totais superiores. Influência do tipo de polimento. Cienc Odontol Bras 2006 jan./mar.; 9 (1):6-16.

7. Kulak Y, Arikan A, Albak S, Okar I, Kazazaoglu E. Scanning electron microscopic examination of different cleaners: surface contaminant removal from dentures. J Oral Rehabil 1997 Mar; 24(3):209-15.

8. Lamfon H, Porter SR, McCoullough M, Pratten J. Formation of Candida albicans biofilms on non-shedding oral surfaces. Eur J Oral Sci 2003 Dec; 11(6):465-71.

9. McCullough MJ, Ross BC, Reade PC. Candida albicans: a review of its history, taxonomy, epidemiology virulence attributes and methods of strain differenciation. Int J Oral Maxillofac Surg 1996 Apr, 25(2):136-44.

10. Moura JS, da Silva WJ, Pereira T, Del Bel Cury AA, Rodrigues Garcia RC. Influence of acrylic resin polymerization methods and saliva on the adherence of four Candida species. J Prosthet Dent 2006 Sept; 96(3):205-11. 
11. Radford DR, Sweet SP, Challacombe SJ, Walter JD. Adherence of Candida albicans to denture-base materials with different surface finishes. J Dent 1996 sept; 26(7):577-83.

12. Rego MRM, Kitahara FMF, Santiago LC. Resina acrílica: relação entre tratamento superficial e retenção de placa bacteriana. Cienc Odontol Bras 2005 jul./set.; 8(3):92-8.

13. Rodrigues EA, Reis RF, Camargo RW. Eficácia de três desinfetantes em próteses totais à base de resina acrílica. Odontol Mod 1994 abr./ jul.; 21(2):11-5.

14. Silva CRG, Jorge AOC. Avaliação de desinfetantes de superfície utilizados em Odontologia. Pesqui Odontol Bras 2002; 16(2):107-14.

15. Spiechowicz E, Santarpia RP, Pollock JJ, Renner RP. In vitro study on the inhibiting effect of different agents on the growth of Candida albicans on acrylic resin surfaces. Quintessence Int 1990 Jan;21(1):35-40.

16. Tawara Y, Honma K, Naito Y. Methicillin-resistant Staphylococcus aureus and Candida albicans on denture surfaces. Bull Tokyo Dent Coll 1996 Aug;37(3):119-28

17. Vianna ME, Gomes BP, Berber VB, Zaia AA, Ferraz CC, de SouzaFilho FJ. In vitro evaluation of the antimicrobial activity of chlorhexidine and sodium hypochlorite. Oral Surg Oral Med Oral Pathol Oral Radiol Endod 2004 Jan;97(1):79-84.
18. Westphal FL, Lima LC, Ferreira CA, Carvalho MA. Tratamento cirúrgico de pneumonia necrosante: análise de quatro casos. J Pneumologia 2000 jan./fev; 26(1):1-4.

19. Wichelhaus A, Bader F, Sander FG, Krieger D, Mertens T. Effective disinfection of orthodontic pliers. J Orofac Orthop 2006 Sept; 67(5):316-36.

20. Williams DW, Lewis MAO. Isolation and identification of Candida from the oral cavity. Oral Dis 2000 Jan; 6(1):3-11.

21.Zissis AJ, Polyzois GL, Yannikakis SA, Harrison A. Roughness of denture materials: a comparative study. Int J Prosthodont $2000 \mathrm{Mar} /$ Apr;13(2):136-40

Recebido em: 21/12/06

Aprovado em: 20/04/07

Endereço para correspondência Thaís Cachuté Paradella

e-mail: tparadella@yahoo.com

Rua Ermínio Neves da Silva, 222

Condomínio Sunset Park - Parque Residencial Aquarius São José dos Campos, SP - Brasil - 12246-008 Tel: 12 3922-5539 - Fax: 12 3947-9010 